\title{
RESEARCH REPORT \\ REVISITING A SMALL PART OF THE EARLY WORK OF LAMARCHE AND COLLABORATORS IN SOUTH AMERICA
}

\author{
MARÍA LAURA SUAREZ* \\ Laboratorio Ecotono, INIBIOMA-CONICET, Universidad Nacional del Comahue, Quintral 1250, 8400 San Carlos de \\ Bariloche, Argentina
}

\begin{abstract}
One of the most extensive dendrochronological field collections in South America was conducted by LaMarche and collaborators from 1973 to 1978. However, no robust chronologies had been developed from these species and/or sites because there were not enough samples collected, or simply because the materials were never processed. Here, I report on results from a re-examination of all Nothofagus dombeyi samples collected during LaMarche and collaborators' field sampling in South America. A tree-ring chronology was developed for the Alto Vilches site in Chile. For the other sites sampled by LaMarche and collaborators, there were not enough samples, or series were not sufficiently long to build a chronology or to provide adequate information about tree growth. The Alto Vilches (VIL) chronology extends into the early 1800 s, and shows high mean sensitivity values and a strong common signal. As expected, the VIL chronology evidenced narrow rings for several years that correspond with low precipitation periods in Patagonia. Making available the information kept in unprocessed tree-ring samples reinforces the dendrochronological potential of this species and strengthens chronology networks developed for ecological studies in northern Patagonia. Finally, this study honors the initial work of LaMarche and collaborators and provides closure to a small part of it.
\end{abstract}

Keywords: Tree rings, Nothofagus dombeyi, Coihue, Chile, precipitation.

\section{INTRODUCTION}

Dendrochronology in South America began in 1943 with the first Fitzroya cupressoides sample collection conducted by Patton in southern Chile (Schulman 1956). Then, Schulman (1956) carried out sampling in Argentina and Chile and built the first chronology of $F$. cupressoides and Araucaria araucana. Ultimately, La Marche and collaborators conducted one of the most extensive dendrochronological collections ever in South America from 1973 to 1978 (Holmes 1978; LaMarche et al. 1979a). They collected samples in Argentina and Chile, and assessed the dendrochronological potential for several endemic species. The general procedure was to collect increment core samples from multiple trees in geographically limited and ecologically homogeneous sites throughout Argentina and Chile.

\footnotetext{
*Corresponding author: marialau.suarez@gmail.com
}

In Argentina they sampled 44 sites, collected cores from 22 species, and built 21 chronologies. In Chile they sampled 18 sites, collected cores from 20 species, and built 11 chronologies. However, a robust chronology comprising all species and sites was not developed, either because there were not enough samples collected, or simply because the materials were never processed.

All the samples collected from 1973 to 1978 by LaMarche and collaborators were housed at The Laboratory of Tree-Ring Research (LTRR), The University of Arizona, Tucson, USA. The LTRR currently houses $c a$. 2,000,000 wood research specimens (http://www.ltr.arizona.edu/collection/), which makes this collection the most unique and diverse in the world. Because the LTRR maintains an archive of dendrochronological samples, all of the materials of LaMarche and collaborators are in an excellent state of conservation, supporting their use in the future (Creasman 2011). This preservation 
of the collection made it possible to inspect and analyze the Nothofagus dombeyi (Mirb.) Blume cores and disk samples collected during LaMarche's widespread fieldwork in South America.

In the past few years, extreme climatic conditions have caused an increase in the mortality rate of $N$. dombeyi (Suarez and Kitzberger 2010), which has sparked more interest in its growth pattern and climatic sensitivity. This has also led to the development of the first preliminary chronology network for Northwest Patagonia, Argentina (Suarez 2010). Because of the growing interest regarding such species, the objective of this study was to process and analyze all $N$. dombeyi samples collected during LaMarche and collaborators' field sampling in South America. The development of a new $N$. dombeyi chronology strengthens the dendrochronological potential of this species, but also contributes to the development of a chronology network encompassing its entire distributional range. Tree-ring chronology networks will contribute highly reliable records for the interpretation of past climate and ecological processes in northern Patagonia. Finally, I believe that this study will honor the initial work of LaMarche and collaborators and complete a small part of it.

\section{LAMARCHE AND COLLABORATORS' SAMPLING}

Data from the collection were extracted from Tree-Ring Chronologies of the Southern Hemisphere, Argentina and Chile (LaMarche et al. 1979a, 1979b). Site descriptions, species collected, and chronologies built from analyzed samples can be found in these two reports, and in Holmes (Holmes 1978). In Argentina, Nothofagus dombeyi (NODO) collection sites were Lago Epuyen (with EPU-2 cross-section found, $40^{\circ} 09^{\prime} \mathrm{S}, 71^{\circ} 33^{\prime} \mathrm{W}$ ), Rio Cisne (RCS- 5 cores found, $42^{\circ} 37^{\prime} \mathrm{S}, 71^{\circ} 54^{\prime} \mathrm{W}$ ), and the Bariloche Area (BAR-2 trees, 1 core/tree, $\left.41^{\circ} 46^{\prime} \mathrm{S}, 71^{\circ} 38^{\prime} \mathrm{W}\right)$. In Chile, the NODO collection was from Alto Vilches (VIL-11 trees/38 cores). The numbers of cores and cross-sections collected in Argentina were low, and only Alto Vilches in Chile was suitable for building a site chronology. Alto Vilches belongs to the Maule Region, one of the regions most affected by the earthquake that occurred in Chile on February 27, 2010. Samples were collected in December 15, 1976, by R. H. Holmes, P. W. Dunwiddle and J. Gutierrez. Samples were taken from a dense, mixed-age forest of small and medium size $N$. dombeyi, and some very large NODO and Nothofagus obliqua (NOOB) (LaMarche et al. 1979b). The site was 80 kilometres southeast of Talca, $35^{\circ} 36^{\prime} \mathrm{S}, 71^{\circ} 00^{\prime} \mathrm{W}$, 1200-1335 m a.s.1.

As described in both Tree-Ring Chronologies of the Southern Hemisphere reports for Argentina and Chile (LaMarche et al. 1979a, 1979b), the general procedure of sampling was to collect increment cores from several radii in each selected tree. Selected trees were on a geographically limited and ecologically homogeneous site. Collected disk cross-sections belonged to stumps or logs of recently felled trees. An embossed aluminium tab bearing the identification number was attached to each sampled tree.

\section{CHRONOLOGY DEVELOPMENT}

I searched the LTRR collection for all NODO core and cross-section samples. I found that all the samples from Argentina had been processed by their collectors. However, Alto Vilches samples from Chile had been mounted but not sanded. Therefore, I processed all samples following the procedures of Stokes and Smiley (1968). Following Schulman (1956), the date of an annual ring was assigned to the calendar year when growth began (September-October in the Southern Hemisphere). The identification of the tree rings was done under a stereo microscope. Individuals exhibited signature years, and hence visual crossdating was initially conducted. I measured the tree-ring widths under a stereo microscope, using a Velmex measuring bench (0.01 $\mathrm{mm}$ resolution). The quality of dating was examined using the COFECHA program ( $\mathrm{r}=$ 0.573) (Holmes 1983), and using a $N$. dombeyi chronology developed from sites on the west side of the Andes (Suarez 2010). Chronologies were standardized using ARS41_win (Cook and Krusic 2006). To remove age and other non-climatic trends, each tree-ring width series was standardized 


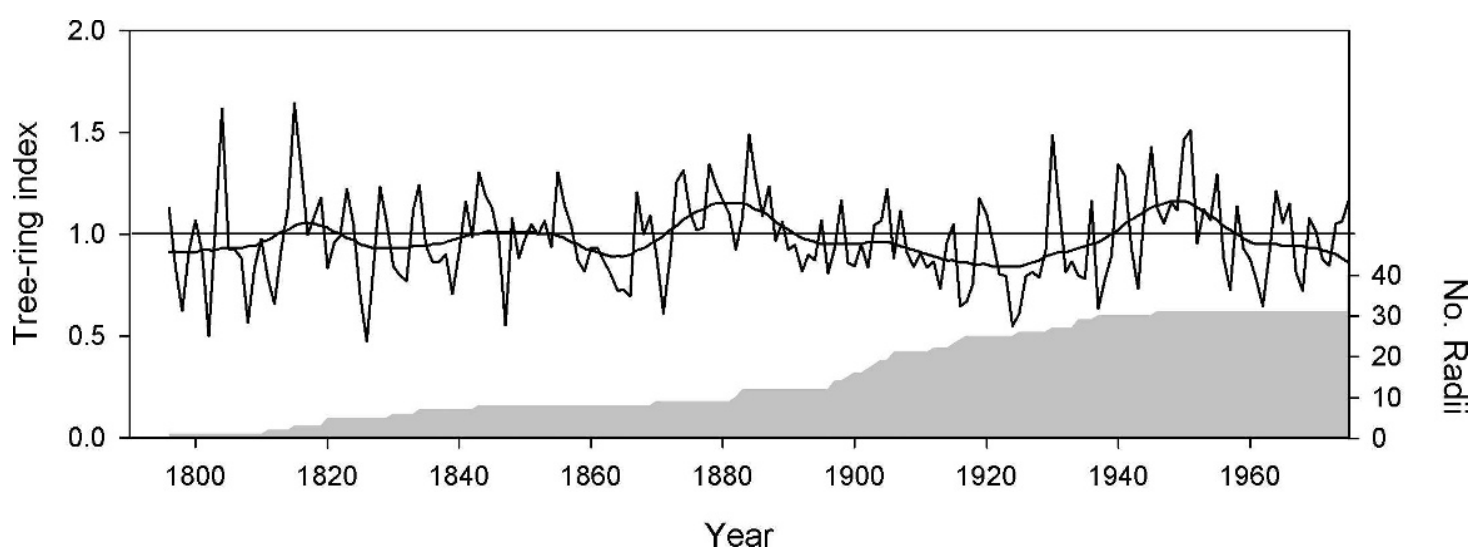

Figure 1. Standard chronology from the Alto Vilches site in Central Chile, showing the number of samples for each year.

using a deterministic model defined by a negative exponential curve (Cook 1985). A biweight robust mean was used to build the mean chronology. To remove the autocorrelation, autoregressive moving-average (ARMA) time-series models were applied. The confidence and reliability of the chronologies were evaluated by quantifying the degree to which a particular sample chronology portrays the hypothetically perfect chronology. This was done using the Expressed Population Signal (EPS) with acceptable statistical quality above the Wigley et al. (1984) threshold of 0.85 .

\section{DERIVED CHRONOLOGY}

A tree-ring chronology was developed for Alto Vilches site. For the other sites sampled by LaMarche and collaborators, there were not enough samples, or series were not sufficiently long to build a chronology or to provide adequate information about tree growth. During the fieldwork done in Alto Vilches, the researchers collected 38 cores from 11 trees (NODO). I successfully processed and measured the total amount of collected series. However, only 31 series could be effectively dated, a significant quantity considering the typically high rate of excluding $N$. dombeyi samples during the crossdating process (Suarez 2010). A correlation coefficient of 0.37 (based on 40-year segments with 20 -year overlapping periods) was selected as the threshold in COFECHA for the inclusion of the individual samples in the site master chronology, as the mean length of series was 90 years. Correlation coefficients below this threshold were related to individuals seriously affected by local disturbances and showing reduced common variance with the other trees included in the chronology.

The Alto Vilches (VIL) chronology extended into the early 1800s (Figure 1 and Table 1). The individual chronology possesses relatively strong common signal, as illustrated by its high interseries correlation (Table 1). However, the distance between sampled trees is unknown. The mean sensitivity of the VIL standard chronology was higher than values observed for a preliminary chronology network of $N$. dombeyi built far south in Argentina (Suarez 2010). However, the present study developed one chronology that although fairly long, was weakly replicated in comparison

Table 1. Descriptive statistics for $N$. dombeyi standard chronologies.

\begin{tabular}{lc}
\hline No. trees & 11 \\
No. radii & 31 \\
Chronology length $^{\mathrm{a}}$ & $1820-1975$ \\
Missing rings $(\%)$ & 0.10 \\
Series intercorrelation & 0.573 \\
Mean sensitivity & 0.203 \\
Mean index (SD) & $0.974(0.219)$ \\
$1^{\text {st }}$ order autocorrelation & 0.379 \\
AR (n) & AR 1 \\
Signal-to-noise ratio & 2.24
\end{tabular}

${ }^{a}$ Chronology length considering more than 5 samples. 


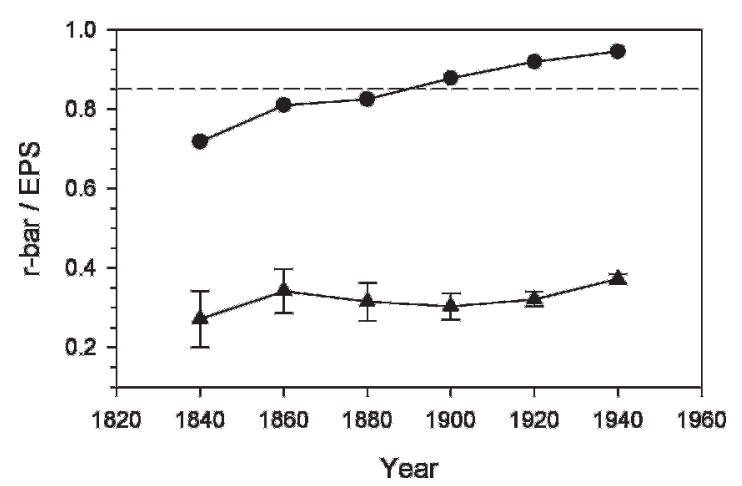

Figure 2. Running average correlation between all series (r-bar, triangles) and expressed population signal (EPS, circles) of the tree-ring chronology of $N$. dombeyi based on a 40-year window with 20 -year overlaps. The acceptable statistical cutoff point for EPS is 0.85 .

with other $N$. dombeyi chronologies which range 50 to 130 trees. As reported previously, this mean sensitivity value is lower than other Nothofagus species, but still suggests that radial growth reflects interannual variations in climate. In addition, the VIL chronology shows high persistence in radial growth as is commonly expected for evergreen species with pre- and neo-shoot formation (Puntieri et al. 2000).

Signal strength, measured by running r-bar, was adequate for this species, and a good measure of strength of the common growth signal within the chronology (Figure 2). However, values for chronology reliability measured by running EPS were always near the threshold (0.85) up to 1890 and were above the threshold after this year (Figure 2). As the EPS is a function of the r-bar and is influenced by series replication, I expected low values of chronology reliability (Briffa and
Jones 1990). Despite LaMarche and collaborators collecting up to four radii per trees, increasing the number of trees rather than increasing the number of radii would be necessary in order to obtain a more reliable chronology.

As reported previously, the growth of $N$. dombeyi is generally negatively and positively influenced by temperature and precipitation, respectively, from November to February (Suarez 2010). Unfortunately, near the sampled site the precipitation and temperature records are not long enough to allow an accurate inspection of the climate-growth relationship for NODO at Alto Vilches. Nevertheless, a simple correlation between Concepción precipitation (1913-1975) and temperature (1951-1975) records (http://climexp. knmi.nl) showed that tree-growth in Alto Vilches was positively related to precipitation during the growing season $(r=0.28, p=0.02)$, but showed no relationship to temperature $(\mathrm{r}=-0.10, \mathrm{p}=$ 0.60). Moreover, the VIL chronology shows patterns of growth similar to chronologies developed in Argentina (Table 2). Tree-growth variations from the Alto Vilches site significantly correlated with those recorded at the stands growing in mesic locations on the eastern side of the Andes (LLA and ESP chronologies). Thus, there is concordance of the missing and narrow rings found in VIL chronology with those reported for Patagonian chronologies (i.e. 1956, 1962), which are coincident to dry periods registered in Patagonia during the $20^{\text {th }}$ Century. The absence of a relationship with temperature was in agreement with climate-growth relationship found for another site on the eastern side of the Andes at $1400 \mathrm{~m}$ a.s.l. (Suarez, unpublished data).

Table 2. Correlations between the Alto Vilches chronology (VIL) and six chronologies developed in the Suarez (2010) study. Period used for the analysis: 1911-1975. The correlation coefficients were calculated using residual chronologies. Significance: ${ }^{*}=\mathrm{p}<$ $0.01,+=\mathrm{p}<0.05$.

\begin{tabular}{|c|c|c|c|c|c|c|c|}
\hline & LLA & GUT & RAP & PIC & ESP & TRO & VIL \\
\hline LLA & - & $0.283^{+}$ & $0.376^{*}$ & $0.384^{*}$ & 0.180 & 0.43 & $0.223^{+}$ \\
\hline GUT & & - & $0.573^{*}$ & $0.675^{*}$ & $0.522 *$ & $0.429^{*}$ & 0.174 \\
\hline RAP & & & - & $0.514^{*}$ & $0.330^{*}$ & 0.97 & 0.185 \\
\hline PIC & & & & - & $0.601 *$ & $0.512 *$ & 0.161 \\
\hline ESP & & & & & - & $0.573^{*}$ & $0.262^{+}$ \\
\hline TRO & & & & & & - & 0.078 \\
\hline VIL & & & & & & & - \\
\hline
\end{tabular}


Nothofagus dombeyi is an evergreen species that grows in Argentina and Chile, which is presently the focus of research by the tree-ring community because of its high mortality related to extreme climatic events (Suarez and Kitzberger 2010). Improved understanding of growth pattern obtained from $N$. dombeyi chronologies would be valuable in future studies about climatic sensitivity, growth, and forest trajectories under global warming scenarios. In the same way, $N$. betuloides has recently shown good potential for the study of climatic variability in Chile (Jara 2011). Thus, a new chronology of $N$. dombeyi developed on the west side of the Andes can help these studies. However, the main goal of this study was to assess and complete a small part of the work performed by La Marche and collaborators in South America and samples stored at the LTRR. I believe that publicizing the information in the unprocessed tree-ring samples also honors their legacy in the tree-ring community.

\section{ACKNOWLEDGMENTS}

The opportunity for searching the LTRR collection and giving a useful end to a part of LaMarche and collaborators work done in South America was only possible thanks to an Agnese N. Haury Visiting Scholar \& Trainee Fellowship and to Don Falk. The author is extremely grateful to Thomas W. Swetnam, Ana Martinez and Lori Wilson for their invaluable help. Also I thank Rex Adams for his assistance in finding $N$. dombeyi samples at the LTRR.

\section{REFERENCES CITED}

Briffa, K., and P. D. Jones, 1990. Basic chronology statistics and assessment. In Methods of Dendrochronology - Applications in the Environmental Science, edited by E. R. Cook, and L. A. Kairiukstis, pp. 240-247. Kluwer Academic Publishers, Dordrecht.

Cook, E. R., 1985. A Time-Series Analysis Approach to Tree Ring Standardization. Ph.D. dissertation. University of Arizona, Tucson.
Cook, E. R., and P. J. Krusic, 2006. ARSTAN_41: A Tree-Ring Standardization Program Based on Detrending and Autoregressive Time Series Modeling, with Interactive Graphics. Tree-Ring Laboratory, Lamont Doherty Earth Observatory of Columbia University, New York.

Creasman, P. P., 2011. Basic principles and methods of dendrochronological specimen curation. Tree-Ring Research 67:103-115.

Holmes, R. L., 1978. Informe preliminar sobre el trabajo de terreno en Argentina y Chile 1975-1978. Instituto Argentino de Nivología y Glaciología (IANIGLA), Mendoza, Argentina.

- 1983. Computer-assisted quality control in tree-ring dating and measurement. Tree-Ring Bulletin 43:69-75.

Jara, J. C. L., 2011. Relaciones entre el crecimiento de Nothofagus betuloides y el clima local y de gran escala en bosques subantárticos de la Isla Navarino. Undergraduate thesis, Universidad Austral de Chile, Valdivia.

LaMarche, V. C., R. L. Holmes, P. Dunwiddie, and L. Drew, 1979a. Tree-Ring Chronologies of the Southern Hemisphere 1. Argentina. Laboratory of Tree-Ring Research, University of Arizona, Tucson.

- 1979b. Tree-Ring Chronologies of the Southern Hemisphere 2. Chile. Laboratory of Tree-Ring Research, University of Arizona, Tucson.

Puntieri, J. G., M. S. Souza, D. Barthélémy, C. Brion, M. Nuñez, and C. Mazzini, 2000. Preformation, neoformation, and shoot structure in Nothofagus dombeyi (Nothofagaceae). Canadian Journal of Botany 78:1044-1054.

Schulman, E., 1956. Dendroclimatic changes in semiarid America. University of Arizona Press, Tucson.

Stokes, M., and T. Smiley, 1968. An Introduction to Tree-Ring Dating. University of Chicago Press, Chicago.

Suarez, M. L., 2010. Tree-ring records from Nothofagus dombeyi: A preliminary chronology network in Northern Patagonia, Argentina. Dendrochronologia 28:65-72.

Suarez, M. L., and T. Kitzberger, 2010. Differential effects of climate variability on forest dynamics along a precipitation gradient in northern Patagonia. Journal of Ecology 98: $1023-1034$.

Villalba, R., and T. T. Veblen, 1998. Influences of large-scale climatic variability on episodic tree mortality in northern Patagonia. Ecology 79:2624-2640.

Wigley, T. M. L., K. Briffa, and P. D. Jones, 1984. On the average value of correlated time series, with applications in dendroclimatology and hydrometeorology. Journal of Climate and Applied Meteorology 23:201-213.

Received 12 April 2013; accepted 31 October 2013. 